\title{
CARACTERÍSTICAS DEL LENGUAJE POLÍTICO: LA DESIGNACIÓN
}

\author{
Miguel Ángel Rebollo Torío
}

El empleo del lenguaje vinculado al término de política no constituye un maridaje anómalo, más bien es un fenómeno sobre el que se trabaja cada vez más. La atracción que ambos elementos ejercen sobre los estudiosos no se limita a un campo concreto de investigadores: lingüistas, sociólogos, periodistas, historiadores y otros profesionales se han acercado, desde ángulos muy diversos, a esa unión establecida entre lenguaje y política. Pensemos, por ejemplo, en las múltiples posibilidades a la hora de denominar unos hipotéticos estudios: lenguaje de los políticos, política del lenguaje, lenguaje político, lenguaje y política, lenguaje de la política o inclusive lenguaje politiqués ${ }^{1}$. Éstos no son los únicos sintagmas ni la única manera de intentar ordenar la relación entre los dos términos. El acercamiento de los estudiosos al lenguaje político es muy diverso: se puede intentar analizar las palabras pertenecientes a una época determinada con el fin de establecer el sistema de interrelaciones entre los diversos $\operatorname{campos}^{2}$; puede también el investigador ceñirse más concretamente a, por ejemplo, el desarrollo de un debate ${ }^{3}$; quizá prefiera tratar de describir las peculiaridades del lenguaje que manipulan los políticos ${ }^{4}$; tal vez opte uno por

\footnotetext{
${ }^{1} \mathrm{Al}$ "lenguaje de los políticos" se refiere F. Mellizo en "Del lenguaje y la política" en El idioma español en las agencias de prensa, compilación de G. Sánchez Ruipérez y Agencia EFE, Madrid, Fundación G. Sánchez Ruipérez, 1990, 133-134, y lo define así: "instrumento de dominio, que nace en el mismo momento en que nace la primera sociedad". La "política del lenguaje" está omnipresente en todas las sociedades, y si se quiere observar no hace falta salirse de los límites de nuestro Estado. Tal vez se entiendan mejor las variantes de "política lingüística" o "planificación lingüística". "Lenguaje político" es el título de un libro que recoge artículos de investigadores diversos, compilado por M. Alvar, Madrid, Fundación F. Ebert, 1987. "Lenguaje y política" pretende ser una forma ecuánime, un binomio equilibrado entre sí por la conjunción copulativa para evitar suspicacias y predilecciones. Al "lenguaje de la política" dedica E. Coseriu unas cuantas páginas en un artículo recogido en la $o b$. cit. coordinada por M. Alvar. Y, por último, "lenguaje politiqués" recuerda al "dialecto politiqués" del sociólogo A. de Miguel, fórmula empleada en su libro La perversión del lenguaje.

2 Remito a los trabajos de Marina Fernández Lagunilla, Ma Jesús Fernández García o los míos propios entre otros.

3 Así, M. Alvar ha analizado uno de los debates anuales sobre la situación del país: "Lenguaje político: el debate sobre el Estado de la Nación (1989)", LEA, XIII/1, 1991, 5-47.

4 J. L. Martínez Albertos, en la ob. cit. coordinada por M. Alvar, ofrece una muestra interesante de las características de este lenguaje.
} 
concretar qué funciones priman en este tipo de lenguaje ${ }^{5}$; o quiera detenerse en parcelas muy estrictas $^{6}$.

Conviene hacer una advertencia antes de proseguir. El lenguaje político no ha de confundirse nunca con el lenguaje de los políticos entendido en otro sentido muy diferente al indicado hasta ahora. Bajo el "lenguaje de los políticos" cabe comprender lo que señalaba F. Mellizo en la nota citada, es decir, el lenguaje político empleado por los políticos; a esto no hay nada que objetar. Pero los políticos no siempre emplean el lenguaje político. De la misma forma, los juristas no necesariamente tienen que expresarse en el lenguaje jurídico en todas las situaciones de su vida. Sin embargo, el lenguaje de los políticos -sea o no lenguaje político- tiene una gran fuerza de atracción entre la sociedad. El aparato burocrático, que depende de los políticos pues éstos son su cúspide (los "jefes"), y los medios de comunicación como mensajeros, repiten y magnifican lo que oyen o leen. En esta sociedad tan unificada, uniformada, igualitaria en su sentido más ramplón, la manera de expresarse se mimetiza y corremos el riesgo de hablar como ellos, es decir, mal. No debemos echar la culpa de una sociedad mal hablada a los políticos que, a fin de cuentas, no pasan de ser el reflejo de esa sociedad. Sin embargo, a todos preocupa el lenguaje de los políticos por la gran influencia que ejercen. El profesor Alvar se lo plantea en los siguientes términos:

"Mil veces se nos pregunta, o leemos, ¿cómo hablan los políticos? Cuestión capciosa porque el interlocutor sólo quiere una respuesta: muy mal. No me he pronunciado, ni siquiera me pronuncio: he encontrado muchas sorpresas que van desde las formas menos nobles de la elocución a una capacidad muy acusada de creación. Si comparamos este lenguaje con el de otras épocas, probablemente no podremos emitir una respuesta optimista, pero yo no condenaría -sólo- a los políticos. ¿Y el galimatías de los biólogos, de los economistas, y de los lingüistas? ¿Y la chabacanería y plebeyez de nuestra vida colectiva?"7

La "culpa" no es de unas personas concretas, pero el ejemplo que constituye un político en la sociedad frente a la influencia que puede suponer un ilustre académico no tiene comparación...en detrimento del académico, bien entendido. Por eso, el lenguaje de los políticos cobra un interés especial. Esta faceta, tan interesante, no es, sin embargo, el objeto de mis palabras.

El ámbito sobre el que puede recaer la atención de un estudioso es dispar. Naturalmente, en mi opinión, el binomio lengua-política debe entenderse en el sentido de lenguaje político, lo cual quiere decir que el sustantivo y lo sustantivo es el lenguaje, y que el calificativo y lo adyacente es el término político. Cabría oponer así lenguaje político a otros lenguajes, con lo cual se establecen clases o estratos diferentes dentro del lenguaje. De igual

\footnotetext{
5 J. del Rey Morato en La comunicación política (el mito de las izquierdas y derechas), Madrid, Eudema, 1989, G. Leech en su conocida Semántica o M. Duverger en diversos trabajos señalan cómo lo menos importante es la función representativa...y lo demuestran, en mi opinión, sin lugar a dudas.

${ }^{6}$ Así, C. Lleal ha estudiado la forma y estructura del panfleto político y yo mismo he analizado los eslóganes políticos de las elecciones de 1983, 87 y 91 en la Comunidad Autónoma de Extremadura.

${ }^{7}$ M. Alvar: "ar. cit.", p. 36
} 
forma que se estudia el lenguaje administrativo-jurídico o el lenguaje científico, se puede aludir también al lenguaje político. Lo más llamativo en todos los casos se manifiesta en el ámbito del vocabulario. De ahí que esa parcela sea la más analizada, sin ser la única existente $^{8}$. Al igual sucede en los demás ámbitos citados. El lenguaje político no constituye un compartimento estanco ni esotérico. El trasvase de unas esferas con léxico especial a la lengua estándar es un fenómeno bien conocido; pero de ello no debe deducirse, por el contrario, que todos los ciudadanos comprendan de la misma manera los términos propios del vocabulario político. Aquí cabe manifestar una divergencia con las otras clases de lenguaje. Por ejemplo, mientras un "recurso de casación" se manifiesta en una comprensión nítida para el demandante y demandado en el lenguaje jurídico-administrativo, o bien, un "hurto" y un "robo" no tienen confusión posible en ese nivel (por más que a la víctima le resulte lo mismo), en el dominio de lo político la ambigüedad es manifiesta. Aquí no puede olvidarse nunca quién emite el mensaje y en qué contexto se da. Sólo con esas claves será posible interpretar, por ejemplo, qué significan la "revolución" o la "democracia" o, sin acudir a términos tan elementales y genéricos, sería interesante preguntarnos a nosotros mismos qué es eso tan famoso del "cambio del cambio": ¿el cambio al cuadrado?, ¿el recambio?, ¿el cambiazo?, ¿la rectificación...hacia dónde? De manera clara, J. del Rey Morato, en su ob. cit., lo ha expresado así:

"Hay ocasiones en que se deja deliberadamente abierta la capacidad de significar de una expresión, precisamente porque es el emisor el que reduce aquella capacidad inicial de significar, que, paradójicamente, sigue abierta, para que cada uno haga su lectura: en el slogan de la campaña electoral socialista de 1982, "Por el cambio", permitió a cada uno poner allí $s u$ cambio, lo que esperaba que fuera a mejor con el partido que hacía aquella oferta, deliberadamente ambigua" (pp. 152-153)

Hay, por consiguiente, en el lenguaje político una polisemia inherente ${ }^{9}$. Las palabras no significan sino en función de lo que los políticos quieren que signifiquen, sin que tenga que coincidir lo que ellos comprenden con lo que entienden los demás, e incluso, apostando por esa deliberada divergencia y confusión calculadas. Tal vez sea ésa la esfera más cercana a lo que un personaje proponía en el cuento de Alicia en el país de las Maravillas. Por eso nunca podremos desvincularnos de la realidad al tratar del lenguaje político. Las lenguas existen porque hay hablantes, y viceversa. Esta realidad de Pero Grullo se olvida con frecuencia entre quienes nos dedicamos a los estudios lingüísticos.

Las posibilidades de trabajo en el lenguaje político son, según hemos visto, muy distintas. Sin embargo, aquí no voy a considerar ninguna de las enunciadas, sino otra posible que no he desvelado hasta ahora: la designación de los políticos, aspecto que puede llevarnos a conclusiones interesantes, no sólo en el ámbito lingüístico, sino en ámbitos sociales, históricos, etc. Al aludir a la designación que pueda tener un líder no voy a plantear

\footnotetext{
8 Habría que estudiar, desde un punto de vista morfosintáctico, el orden de palabras, los adverbios en -mente tan en boca de los políticos de hoy, el uso de los tiempos verbales, etc.

${ }^{9}$ El lenguaje es polisémico por naturaleza, pero en el caso del lenguaje político se acentúa esa peculiaridad.
} 
nada relacionado con los problemas de si se trata de nombres comunes o propios, tarea a la que se ha dedicado, entre otros, el doctor Ariza, sino a las variaciones en la denominación de los líderes. Esta tarea tampoco es inédita en los estudios sobre vocabulario político. Por señalar a alguien puedo citar dos trabajos, en parte complementarios y en parte polémicos, de los profesores S. Bonnafous y M. B. Throsby, que tratan de líderes franceses ${ }^{10}, y$ también, de manera muy diversa, pues sus objetivos son distintos, a C. Otaola en nuestros propios dominios hispánicos ${ }^{11}$.

S. Bonnafous trataba de "essayer de mettre à jour un principe organisateur des désignations de François Mitterrand dans quelques hebdomadaires nationaux d'actualité politique, choisis pour leur fort tirage et leur répresentativité" (art. cit., 3). Es así como Bonnafous distingue tres tipos principales de designación de Mitterrand: 1) empleo del nombre propio, 2) empleo del título (Jefe del Estado, Presidente), y 3) uso de expresiones metafóricas o metonímicas (Tonton, el Elíseo). El desarrollo de estos tipos lleva a una variedad de usos y a una tipología con la que concluye el artículo. M.B. Throsby se distingue de Bonnafous en que se centra en un único periódico, Libération, y en cuatro candidatos a la elección presidencial francesa de 1988. Además, Throsby distingue seis tipos de designación: 1) el nombre propio, 2) las apelaciones totémicas (terminología de LéviStrauss, que alude al uso de títulos oficiales: primer ministro, diputado de X), 3) los términos de parentesco (entiéndase ideológico y no familiar, como el líder del Frente Nacional, el candidato socialista), 4) las expresiones metafóricas y metonímicas (Tonton, el Elíseo, el Diablo), 5) los términos de relación (referidos a una persona en relación con otra, el aliado de X), y 6) los términos de clase (apenas importantes según el propio Throsby, los 4 candidatos, los dos finalistas). Ambas clasificaciones son posibles, pero no han de imponerse por fuerza; hay que contar sólo con el material de que disponemos.

Veamos, pues, cuál ha sido el punto de partida nuestro, de qué fichas no servimos y, después, reflexionaremos para establecer las conclusiones oportunas.

Las variaciones de designación han constituido desde siempre un problema lingüístico, de tipo onomasiológico. Sin embargo no es nada habitual trabajar con variaciones de seres humanos ${ }^{12}$. El estudio de las designaciones de líderes políticos constituye un enriquecimiento del lenguaje político y proporciona también -y no hay que desdeñarlo- datos de ayuda para otras disciplinas humanísticas en beneficio de un mejor conocimiento de nuestra sociedad, último objetivo de las ciencias.

\footnotetext{
10 S. Bonnafous: "De "M. François Mitterrand" à "Tonton" ou les variations significatives d'une désignation", Cahiers de Lexicologie, XLVI-I, 1985-I, 3-25. M. B. Throsby: "De "Tonton" au "Diable". La désignation des hommes politiques dans Libération en période electorale", Cahiers de Lexicologie, LV, 1989-II, 5-37.

11 C. Otaola Olano: "Estudio de algunas unidades lingüísticas designativas", E.P.O.S., VI, 1990, 147-175, y VII, 1991, 215-234. La autora se propone "descifrar el complejo entramado lingüístico-ideológico que subyace a empleo de determinadas unidades lingüísticas designativas" y "perfilar el contenido semántico de unidades léxicas como árabe, moro y musulmán" en Melilla. Para ello se sitúa en un período determinado de tiempo y se basa en diarios de un amplio espectro ideológico.

12 Análisis sobre los apodos sí son conocidos, pero aquí no se trata exactamente de esto.
} 
Las pasadas elecciones generales al Congreso y al Senado, celebradas el 6 de junio de 1993, constituyen un buen campo de prueba de esta clase de trabajo. Nuestro propósito ha consistido en vaciar unos cuantos periódicos de ámbito estatal, ceñirnos al período estricto de las elecciones ( 21 de mayo a 4 de junio, ambas fechas inclusive, pues el 5 era jornada de reflexión y el 6 de votaciones) y anotar la designación de los cuatro candidatos con implantación en el territorio nacional, presentados como futuros y posibles Jefe de Gobierno, es decir, Felipe González, José Ma Aznar, Julio Anguita y Rafael Calvo Ortega. Por razones de tiempo sólo he podido vaciar un único periódico, El Mundo ${ }^{13}$. Los datos pueden ser discutidos al considerar un único diario, pero sí se puede afirmar que son significativos y en ningún caso desdeñables ${ }^{14}$. Dentro de $E l$ Mundo el vaciado no ha sido total, sino tan sólo de las páginas relacionadas con las elecciones generales, que, en el periódico, venían destacadas por un encabezamiento de un dibujo esquemático del hemiciclo del Congreso con el reparto de escaños y, en su interior, se inscribía la cifra '93.

Para una mejor comprensión de las posibles alteraciones en la designación de los candidatos hay que recordar algunos sucesos. El mismo día en que se inicia oficialmente el período electoral, el 21 de mayo, Felipe González, en calidad de Presidente de Gobierno, recoge en Aquisgrán el Premio Carlomagno. A media campaña, en Barcelona, Julio Anguita sufre un infarto de miocardio que lo retira a la fuerza de mítines y demás actos electorales. Y, por último, es la primera vez que en una TV se ofrecen dos debates entre los dos candidatos de las fuerzas mayoritarias con exclusión de los demás.

Estos datos, que han de ser interpretados más bien por sociólogos, no dejan de tener su repercusión en el empleo de las designaciones y en el favorecimiento de unos líderes que son citados más veces que otros.

En la inmensa mayoría de los casos, las crónicas son de los periodistas. Cuando, por entrecomillarlo o por citar palabras textuales, el emisor sea un dirigente político y no un periodista, lo haré saber. Ahora bien, dentro de los periodistas no hago distinciones entre unos y otros. Indico esto porque la manera de escribir de un F. Umbral, por ejemplo, es muy personal y diferente de la de otros. Pero a efectos estadísticos la división es clara: o son periodistas o son dirigentes políticos.

Empecemos, pues, por las diversas maneras de designar a los líderes ${ }^{15}$. De acuerdo con los materiales de que dispongo, podemos dividir en cuatro los tipos de designación: 1) el nombre propio, 2) el rango administrativo, 3) el liderazgo, y 4) la implicación con otros

\footnotetext{
13 Pese a que es sólo uno no deja de tener interés, pues se trata de un diario joven, con cinco años de vida, y con un crecimiento constante y espectacular en un terreno en el que, por causas que no hacen al caso, han cerrado otros como El Sol, El Independiente y, cuando escribo esto, El $\mathrm{Ya}$ atraviesa una etapa difícil.

${ }^{14}$ En mi apoyo hago notar que Throsby optó exclusivamente por Libération.

15 Ofrezco datos globales cuantitativos. No recojo los datos que se citan en la Agenda, sección dedicada al anuncio de actos y mítines de cada día. De igual manera, al aludir, por ejemplo, al debate González-Aznar, tampoco lo recojo, pues lo sustantivo es el debate y no los contrincantes. Por último, en las aposiciones del tipo "el presidente del partido X, Fulano de Tal", ficho sólo la denominación más importante (comprendo que este criterio puede ser discutido, pero los casos en que esto ocurre son pocos y no afectan al análisis de conjunto). E estudio de la aposición, muy atractivo, es más complejo y he optado por no incluirlo por ahora.
} 
candidatos. Bajo el primero se tratan todas las formas posibles de nombrar a los líderes. Al segundo se recurre para llamar la atención de los lectores por el puesto que desempeña un líder en el Gobierno; claro está que aquí existe un desequilibrio evidente entre los cuatro candidatos, pero creo que este aspecto, por eso mismo, tiene un interés especial ${ }^{16}$. En el tercero se recoge la capacidad de liderazgo de cada uno de los dirigentes políticos, sin equipararlos con nadie. Por último, en el cuarto, hay una liza marcada con los demás.

Empezaré por el candidato del PSOE, seguiré con el del PP, continuaré con el de IU y terminaré por el del CDS. Este recorrido no es caprichoso, va de un más a un menos en la fuerza de los votos.

I. El candidato del PSOE, Felipe González.

a) El nombre propio. La variedad de designaciones del candidato socialista es grande, prueba de los registros tan diversos que tiene ante los electores. Así, Felipe, el nombre de pila simplemente, aparece 74 veces, de las que 68 corresponden a periodistas y 6 a dirigentes diversos. González, un apellido muy corriente en nuestra lengua, aparece 388 veces (365 se deben a periodistas y 23 a dirigentes). El nombre completo, Felipe González, se da en 279 ocasiones (262 en periodistas y 17 en dirigentes). Las iniciales $F G$, hábito cada vez más empleado en el dominio público (recuérdese la huelga general del 14D o el intento de golpe de Estado del 23F) tampoco escapan a los periodistas, quienes se sirven de ellas en 12 ocasiones ${ }^{17}$. Un tratamiento menos llano es el de Don Felipe González, recogido 2 veces en un periodista. Obsérvese que el don es fórmula habitual en el tratamiento de nuestra lengua, $\mathrm{y}$, en cambio, en el lenguaje político el distanciamiento que provoca el usted, subyacente en el don -en el dominio peninsular al menos- se da muy poco, e incluso puede servir como recurso estilístico para otras finalidades. Así sucede con don González, empleado 6 veces por periodistas ${ }^{18}$. En una única ocasión un dirigente de un partido político de ámbito no estatal alude al señor Felipe, fórmula claramente degradante por una parte, pues se encabeza con un señor, y, por otra, de confianza, porque recoge tan solo el nombre de pila. Con señor y el apellido aparece 7 veces, el señor González, de las cuales una se debe a un periodista y seis a dirigentes políticos. En una única ocasión, un corresponsal extranjero destaca en cursiva al tío Felipe, manera muy popular de dirigirse al candidato a la Presidencia del Gobierno. También en otra ocasión, un dirigente señala a Felipe el cínico, sintagma que recuerda a "Felipe el Hermoso" y similares, de amplio y viejo uso en nuestra lengua. Y, por último, un periodista escribe el González líder en una ocasión, donde lo anómalo es la inversión un tanto brusca del orden de palabras. Líder no es término raro, en absoluto, pero sí lo es esta manera de aludir al candidato socialista ${ }^{19}$.

\footnotetext{
${ }^{16}$ En los debates televisados, los moderadores explicaban al principio que, pese a que uno de los contendientes era el Presidente del Gobierno en funciones, allí tenían el tratamiento de señores candidatos los dos. Este principio no se lleva a rajatabla en la prensa, según veremos.

17 Ningún dirigente político alude nunca a FG. Y los periodistas que emplean esta fórmula son F. Umbral y P. Urbano.

18 En todos los casos es Francisco Umbral.

${ }^{19}$ No entro en el tipo de artículos que encabezan las fórmulas ni en su ausencia tan significativa.
} 
La gran variedad de designaciones agrupadas bajo el rótulo del nombre propio no agotan este catálogo. Faltan otras, metafóricas, nada raras en lo que se refiere a la metáfora, sí sorprendentes, en cambio, en el contexto democrático en que se sitúan ${ }^{20}$. En una ocasión un periodista entrecomilla el término dios referido a Felipe González ${ }^{21}$ y una vez más otro alude al dios González para que no haya dudas.

Menos insólita que estas dos últimas es la equiparación con un torero, metáfora muy hispana, recogida 1 vez por un periodista, que surge cuando Felipe González no acude a un mitin en Murcia y sustituye al primer espada el vicesecretario del PSOE Alfonso Guerra.

Bajo la agrupación del nombre propio se acogen 14 variantes: Felipe, González, Felipe González, FG, Don Felipe González, don González, señor Felipe, señor González, tío Felipe, Felipe el cínico, González líder, dios, dios González y primer espada. En total suman 775 alusiones, de las cuales tan sólo 52 pertenecen a dirigentes políticos diversos ${ }^{22}$.

b) Puesto administrativo. Este segundo bloque es más discutible y difícil de encasillar que el primero porque se trata de alusiones a cargos en la Administración del Estado. Sin duda, el más aludido, por ser el único posible, es el líder socialista y Jefe del Gobierno en el momento en que se convocan las elecciones. Ahora bien, semejantes alusiones no pueden ser olvidadas. Recordemos que la campaña electoral se inicia el día en que Felipe González recoge en Aquisgrán un título. La prensa, en consecuencia, menciona a F. González por el puesto administrativo que ocupa. Que este hecho sea o no reprobable no nos compete aquí, lo importante es que se alude de una manera determinada a un candidato y como tal lo recojo. A ello responde que, en una ocasión un periodista nombre al Jefe de Gobierno y en otra ocasión se dirija al presidente, que sólo puede serlo del Gobierno, pues en su partido es secretario y no presidente. En cinco ocasiones, para que no haya dudas, se le nombra como el Presidente Felipe González. Pero la mayoría de las veces, 43, la fórmula empleada es la de Presidente del Gobierno, siempre entre periodistas.

En otras ocasiones, la prensa se hace cargo de la provisionalidad de un gabinete en fase de elecciones y marca esa circunstancia de maneras diversas: el actual jefe del Ejecutivo (una vez), el presidente en funciones (una vez), el actual presidente (5 veces) ${ }^{23}$, el ahora Presidente del Gobierno en funciones (una vez), y, por último no falta la acumulación, dos veces, del presidente y candidato socialista [a la presidencia del Gobierno].

En total hay 9 variantes para marcar el cargo que ocupa el líder socialista, indicando unas veces que es el "jefe de Gobierno" (con sus variantes correspondientes) y otras que es jefe "provisional" tan sólo. Se trata de: jefe de Gobierno, presidente, Presidente Felipe González,

\footnotetext{
${ }^{20}$ La metáfora está presente en todos los aspectos de la lengua. El lenguaje político no podía ser una excepción (recordemos "el gran timonel", "el capitán del barco", etc.).

${ }^{21}$ El origen se halla en una conversación telefónica del político socialista Txiqui Benegas que, a través de un teléfono móvil, aludía al "dios" y al "number one". La conversación se grabó y difundió por radio.

22 Se entiende que, en sus crónicas, los periodistas alternen unas y otras apelaciones para no repetirse. Este factor se va a dar con todos los líderes políticos, por lo que no es significativo.

${ }^{23}$ La fórmula empleada es más larga en algunos casos, el actual presidente del Gobierno. El complemento nominal no altera la frase, por eso no insisto en este caso y otros semejantes.
} 
el Presidente del Gobierno, el actual jefe del Ejecutivo, el presidente en funciones, el actual presidente, el ahora Presidente del Gobierno en funciones y el presidente y candidato socialista [a la presidencia del Gobierno]. En total son 30 veces el número en que se señala a F. González. Curiosamente ningún dirigente político lo trata de esa forma, corresponden siempre semejantes fórmulas a los periodistas.

c) Liderazgo. Este tercer bloque encara a F. González como la cabeza de su formación política, sin tener que vincularlo a ningún otro candidato. Las variantes son también posibles, así en una ocasión un periodista alude escuetamente a un líder, por el contexto es el socialista. Sin embargo, es más habitual hacer inequívoco el señalamiento. El líder socialista aparece 14 veces entre los periodistas. Otras veces es el líder del PSOE (5 veces) y en una ocasión, también entre periodistas, el líder del Partido Socialista ${ }^{24}$.

En lugar de la voz líder, se puede recurrir a otras palabras como en el caso del Secretario General del Partido Socialista (5 veces los periodistas), o bien el secretario general [del PSOE] (11 veces, periodistas) ${ }^{25} \mathrm{y}$, por último, en dos ocasiones se alude al secretario general de los socialistas ${ }^{26}$. Con otro elemento adyacente, y con intenciones peyorativas, dirigentes políticos adversos, citan dos veces al secretario general de Filesa ${ }^{27}$, y situándose en el futuro, un político sitúa a F. González como perdedor de las elecciones y jefe de la oposición (una vez) ${ }^{28}$.

En total, se nombra como líder, de 8 formas distintas, a Felipe González un total de 42 veces, de las cuales sólo 3 pertenecen a no periodistas, y, significativamente, éstas tienen aviesas intenciones políticas. En los 39 casos restantes se busca la neutralidad y la mayor asepsia.

d) Implicación con otros candidatos. En este apartado todas las variantes están encabezadas por el término candidato, y lo único que difiere es el elemento adyacente. Una vez es el candidato a la reelección, en otra será candidato a Presidente, 8 veces aparece como candidato [presidencial] del PSOE ${ }^{29}$, en otra ocasión es el candidato del Partido Socialista, y

\footnotetext{
24 Obsérvese el acortamiento del partido. En las siglas es PSOE; el enunciarlo, tan sólo Partido Socialista. Las dos palabras finales, correspondientes a Obrero Español, se pierden sin que afecte a la comprensión.

25 Unas veces se indica "del PSOE" y otras basta el contexto para establecer de quién se trata.

26 Es curiosa la insistencia en el adjetivo "general". Es bien sabido que "secretarios" hay muchos más y que "general" sólo puede serlo el de todo el partido, y no el de una agrupación o federación, pero no deja de ser redundante en $\epsilon$ l contexto en el que se sitúa, por lo que se convierte ya en un cliché.

27 El llamado caso "Filesa" constituyó un escándalo entre las filas socialistas. Actualmente está a la espera de diligencias y conclusiones judiciales. Los adversarios se sirven, políticamente, del escándalo para incidir en la corrupción supuesta de los socialistas.

${ }^{28}$ La acuñación de "jefe de la oposición" se debe a los socialistas. Cuando M. Fraga era el líder de AP, aceptó ese título. J. M M $^{a}$ Aznar, en cambio, no lo quiere. En realidad "jefe de la oposición" hace aparecer como todo un bloque opuesto al gobierno a todos aquellos que no están con el poder, con lo cual, fuerzas de IU, del CDS y otras quedarían agrupadas bajo la "jefatura" de AP. Esto es absurdo en la vida parlamentaria, pero en la lengua se recoge así.

${ }^{29}$ De las ocho veces tan sólo una vez se añade lo de "presidencial".
} 
19 veces el candidato socialista [a la presidencia del Gobierno]. Siempre son periodistas los emisores. En total hay cinco variantes y 30 alusiones.

En resumen, Felipe González aparece mencionado en 877 ocasiones [775+30+42+30], de las cuales sólo 55 se deben a dirigentes políticos diversos. Con una gran diferencia la fórmula predominante es la del nombre propio, que supone 775 veces del total. Es también la preferida por los no periodistas, pues 52 veces nombran a Felipe González de esa forma. Las alusiones entre periodistas y no periodistas es muy grande, de un $93{ }^{\prime} 72 \%$ a un 6'27\%, y la que va de la preferencia del nombre a las demás también. El bloque a) supone un $888^{\prime} 36 \%$, el b) un $3^{\prime} 42 \%$, el c) un $4^{\prime} 78 \%$ y el d) un 3'42\%. Además, todas las subvariantes de cada bloque suman $36[14+9+8+5]$, pero se reparten de manera distinta, pues los porcentajes son los siguientes: a) $38 ' 88 \%$, b) $25 \%$, c) $222^{\prime 22}$ y d) $13{ }^{\prime} 88 \%$. No hay simetría entre alusiones y variantes. Mientras las menciones del grupo a) constituían un $88^{\prime} 36 \%$, las variantes de ese mismo bloque suponen un 38 ' $88 \%$. Hay un mayor reparto entre las variantes que entre las alusiones.

II. El candidato del PP, José María Aznar.

a) El nombre propio. El líder del PP tiene nombre compuesto y como tal, en bloque, aparece escrito sin abreviaturas, José María y no *José $\mathrm{M}^{\mathrm{a}}$ ni familiaridades del tipo *Pepe o *Pepemari. Ahora bien, el empleo de este nombre propio se recoge dos veces y se debe al propio Aznar que se alude a sí mismo de esa manera. Ni otros dirigentes políticos ni los periodistas presentan un grado de familiaridad equiparable a Felipe. Por el apellido, Aznar, lo nombran 476 veces, de las cuales en 34 ocasiones se trata de dirigentes políticos. Con nombre completo y apellido, José María Aznar hay 164 citas, de las cuales tan sólo 4 pertenecen a no periodistas. Con el tratamiento de don, don José María Aznar, aparece una vez en un periodista, y como el señor Aznar 10 veces, de las cuales 3 pertenecen a dirigentes políticos.

Con un carácter diverso, ambiguo, en una ocasión F. Umbral alude al pequeño Aznar. El calificativo de "pequeño" obedece a la estatura del líder popular, pero "pequeño" puede tener acepciones no estrictamente físicas, por lo que la denominación es confusa. Por último, con un matiz irónico, pues el emisor es un dirigente socialista, se recoge una vez el compañero Aznar.

En total, bajo el nombre propio se dan 7 variantes tan sólo y 655 alusiones, de las cuales 41 son de dirigentes políticos y el resto, 614, de periodistas.

b) Puestos administrativos. El líder del PP no ocupa ningún cargo en el Gobierno. Su situación personal profesional no interesa aquí. No es de esperar, por consiguiente, que aparezca ninguna denominación similar a la de González; sin embargo, las esperanzas de una victoria electoral permiten en una ocasión a un periodista señalar al próximo presidente del Gobierno y, otra vez, aludir al nuevo presidente in pectore. Hay dos variantes y dos alusiones en este apartado. 
c) Liderazgo. Esta característica es vital en cualquier formación. Aznar puede ser saludado como un hombre en una ocasión por un periodista, en el sentido de dirigente. Lo más habitual es aludir al político popular como el líder del PP (33 veces, de las cuales sólo 1 es de un dirigente). En 12 ocasiones se evitan las siglas y se enuncia completamente la formación popular, el líder del Partido Popular, y en 6 es sólo el líder popular, sintagma donde "popular" actúa como equivalente de "socialista" en la otra formación. Sorprende más la fórmula de líder conservador, consignada 3 veces, en la que se apunta a la ideología y no a la denominación del partido. Obsérvese que no hemos encontrado una fórmula semejante entre los socialistas en el material utilizado, del tipo * líder progresista. Idéntico adjetivo puede aplicarse a otro sustantivo, el dirigente conservador en 2 ocasiones. Bajo la forma del líder todavía hay otras maneras de señalar; así, se escribe 2 veces sobre el líder de la oposición, en otra se destaca al actual líder de la oposición, dado un carácter de provisionalidad con ese calificativo, otra vez se matiza sobre la clase de oposición, el líder del principal partido de la oposición, e, incluso, se recurre una vez a la fórmula comentada antes de jefe de la oposición. Y, por último, caben todas las posibilidades de señalar al líder por el cargo que ocupa en su partido. Así, 1 vez será el presidente nacional del Partido Popular, con un adjetivo "nacional" que es el correspondiente del "general" entre los socialistas, o bien, sin dicho calificativo, 7 veces recojo el Presidente del Partido Popular, en 13 ocasiones se alude al presidente del PP, de las cuales 1 de ellas es de un dirigente político, y una última señala al Presidente de esta formación. Como lapsus calami hay que recoger el que un periodista $(26-\mathrm{V}$, p. 10), o el linotipista si es que existe todavía, aluda al secretario general del $P P$, pues, si no lo he interpretado incorrectamente, apunta a José $\mathrm{M}^{\mathrm{a}}$ Aznar. Y en el PP, como sucede en los partidos de derechas, los líderes máximos no son sus secretarios, sino sus presidentes. En cambio, en la izquierda, el fenómeno es inverso.

En total tenemos 14 variantes (no cuento la errónea) y 84 alusiones, de las cuales 2 únicamente pertenecen a dirigentes políticos.

d) Implicación con otros candidatos. Igual que en el caso del líder socialista, candidato es el término fundamental para marcar la pugna por la presidencia del Gobierno. Así sucede 1 vez con el candidato conservador, 3 veces se alude al candidato del Partido Popular a la presidencia del Gobierno, en 27 ocasiones, de manera más corta, se escribe sobre el candidato del PP [a la Presidencia del Gobierno] y 10 veces es el candidato popular [a la Presidencia del Gobierno]. Con esto no se agotan las diferentes maneras de señalar al candidato del PP; también puede ser conocido, 1 vez, como el oponente conservador, y 7 veces como el aspirante [a Jefe de Gobierno], variantes, ambas, insólitas y aplicadas exclusivamente a Aznar. Da la impresión, en la lengua, de que los demás ni son oponentes ni tienen ninguna aspiración de llegar a la meta codiciada.

En este apartado aparecen 6 variantes (sin diferenciar entre formas cortas y largas) y 49 alusiones al político, todas pertenecientes a periodistas.

En total, José $\mathrm{M}^{\mathrm{a}}$ Aznar aparece mencionado en 790 ocasiones [655+2+84+49], de las cuales sólo 43 se deben a dirigentes políticos diversos. Igual que sucedía con F. González, predomina el empleo del nombre propio, 655 veces en total, y es también el preferido por 
los no periodistas, con una diferencia de un $94 ' 55 \%$ a 5'44\%. Por bloques, el porcentaje es el siguiente: el a) tiene un $82^{\prime} 91$, el b) un $0^{\prime} 25 \%$, el c) un $10^{\prime} 63 \%$ y el d) un 6'20\%. Entre las variantes, $29[7+2+14+6]$, la distribución es como sigue: a) $2413 \%$, b) 6'89\%, c) $48 ' 27 \%$ y d) $20 ' 68 \%$. Los datos no guardan simetría ni con los anteriores por alusiones al propio Aznar, ni con los correspondientes a F. González. Dejaremos las consideraciones globales para el final, cuando hayamos establecido la situación de los líderes de IU y del $\mathrm{CDS}^{30}$.

III. El candidato de IU, Julio Anguita.

a) El nombre propio. El líder de la formación de izquierdas tiene muy pocas variantes en relación con los otros dos políticos ya analizados. Por su propio nombre, Julio, solamente existen 4 menciones, dos de F. Umbral y otras dos de dirigentes de IU ${ }^{31}$. La manera más general de aludir al secretario del PCE consiste en emplear su apellido, Anguita, como se da en 167 ocasiones, dos de ellas entre no periodistas. Con nombre y apellido, Julio Anguita, aparece 95 veces (otras dos entre dirigentes). Y, por último, en una sola ocasión, con ánimo jocoso, un periodista alude a julius ${ }^{32}$.

Son únicamente 4 las variantes con 265 apelaciones, de las que sólo 7 pertenecen a no periodistas.

Destaca la ausencia de formas de tratamiento del tipo don o señor y de otras posibles alusiones irónicas.

El apartado b) no existe para J. Anguita. Las posibilidades de que IU alcance el poder son nulas, por lo que no puede, en un futuro inmediato, pensar en ocupar un cargo administrativo, a no ser que exista un juego de alianzas bastante problemático en la actualidad.

c) Liderazgo. Como político que opta a la Presidencia del Gobierno, Anguita es el líder de IU en 18 ocasiones, o bien el líder de Izquierda Unida 3 veces. Con mayor precisión es también el líder de la coalición [Izquierda Unida] otras 3 veces $^{33}$. Además de líder, el trato puede ser de dirigente de IU en 1 ocasión. Pero lo más notable es el empleo de "coordinador", explicable por el puesto que ocupa. Por eso, será coordinador de IU, 4 veces,

\footnotetext{
30 Hay otras denominaciones que no se ajustan ni a F. González ni a José Ma Aznar, se trata de un híbrido: Felipe Aznar (1 vez), el señor Felipe Aznar (1 vez) y el señor "Felipe Aznar" (con comillas en otra ocasión). En los tres casos son apelaciones irónicas de un dirigente del PNV. Lo reseño en nota para mostrar cómo es posible incluso llegar a nuevas variantes, pero no lo cuento en la estadística.

31 En dos ocasiones he leído vítores de la multitud de los mítines que coreaba a "ijulio, julio, julio!". No los incluyo en el recuento porque no están en el mismo plano que las demás.

32 Así lo escribe Jesús Ferrero en un artículo.

${ }^{33}$ La colaboración de varios partidos en una "coalición" justifica el sintagma y, a la vez, excluye, al menos en El Mundo, la apelación a otros términos como podrían ser los de "comunista" y similares. La voz "comunista" tiene nula frecuencia cuando se trata de ver no al secretario del PCE sino al líder de una coalición heterogénea.
} 
y coordinador general $[$ de $I U]=[$ de Izquierda Unida $]$ en 8 ocasiones $^{34}$. Por último, en un único momento será denominado ex alcalde de Córdoba, con idea también de líder, por lo que lo incluyo aquî35.

Las variantes son 7 y las alusiones 38 , todas procedentes de periodistas.

d) Implicación con otros candidatos. En este apartado todo gira en torno al candidato, que unas veces será candidato de Izquierda Unida [a la presidencia] en 8 ocasiones, otras candidato de IU [a la presidencia del Gobierno] (5 veces), y, por último, candidato a la presidencia del Gobierno en dos ocasiones.

Hay tres variantes y 15 alusiones, todas procedentes de periodistas.

El resumen de J. Anguita queda, en consecuencia, así: tiene 318 alusiones [265+0+38+15], de las cuales sólo 7 son de dirigentes políticos y se dan en el apartado a). El empleo del nombre propio predomina sobre todos lo demás. el preferido por todos. La diferencia en uso entre periodistas y no periodistas es de $97165 \%$ y $2^{\prime} 34 \%$. En los bloques, el porcentaje de alusiones es el siguiente: a) $83 ' 33 \%$, b) $0 \%$, c) $11^{\prime} 94 \%$ y d) $4 ' 71 \%$.

Las variantes, $14[4+0+7+3]$, tienen la siguiente distribución: a) $28157 \%$, b) $0 \%$, c) $50 \%$ y d) $21^{\prime} 42 \%$.

IV. El candidato del CDS, Rafael Calvo Ortega.

a) El nombre propio. El candidato centrista muestra muy pocas variantes en el empleo del nombre propio y, además, destaca por dos motivos: a) nunca conoce alusiones sólo por el nombre de pila y b) es el único en el que lo más frecuente es aludir a los dos apellidos ${ }^{36}$. Como Rafael Calvo Ortega es mencionado 15 veces, como Calvo Ortega en 64 ocasiones, y como Ortega una única vez ${ }^{37}$.

Las variantes son sólo 3 y las alusiones 80 , siempre entre periodistas. Tampoco conoce el dirigente de centro menciones en el apartado b).

c) Liderazgo. Como político que opta a la presidencia del Gobierno, Calvo Ortega es el líder del CDS en 6 ocasiones, el líder del Centro Democrático Social 2 veces $^{38}$, o simplemente como el líder centrista en 1 ocasión.

\footnotetext{
34 Marcar explícitamente que es "coordinador" de IU o de Izquierda Unida es redundante. En estas elecciones no hay más coordinador que él, pues las otras tres formaciones estatales son partidos, a cuyo frente habrá presidentes o secretarios, nunca coordinadores.

$35 \mathrm{Creo}$, sin duda, que encaja en este apartado, pues Anguita fue el único alcalde comunista de una capital de provincia, Córdoba, hasta pasar a ocupar el puesto de secretario del PCE en Madrid. Prueba de ello es el apodo con el que se le conoce, el Califa, que, sin embargo, no encuentro entre mis materiales.

${ }^{36}$ En los otros tres políticos el segundo apellido es irrelevante, no ofrece ningún juego en la denominación. En cambio, en el dirigente del CDS, "calvortega" parece único.

37 Apelación francamente extraña. Tal vez pueda justificarse por la necesidad de no repetirse en una crónica muchas veces.

38 El CDS se "traduce" unas veces como "Centro Democrático Social" y otras como "Centro Democrático y Social" según lo recojo en la prensa.
} 
Otro grupo de variantes está encabezado por el término dirigente. Puede ser el dirigente del Centro Democrático y Social (1 vez), el dirigente del CDS (1 vez), el dirigente de la formación centrista (1 vez), y el dirigente centrista en 5 ocasiones.

También tiene alusiones referidas al cargo que ocupa en su partido. Por eso es el presidente del CDS en 13 ocasiones, el Presidente del Centro Democrático Social 1 vez, el Presidente de la formación centrista en otra ocasión, y el presidente centrista 5 veces.

R. Calvo Ortega dispone de 11 variantes y 37 alusiones, procedentes siempre de periodistas.

d) Implicación con otros candidatos. El término candidato es el núcleo de todas las variantes. Unas veces sería el candidato del CDS [a la presidencia del Gobierno] (5 veces), otras el candidato centrista en 9 ocasiones, y una vez más el candidato a la presidencia del Gobierno por el CDS. Además de estas formas, por dos veces se alude al político centrista como el candidato de la triste figura, manera de señalar la utopía que persigue el CDS según todos los indicios preelectorales y que se cumplieron el 6 de junio.

Hay 4 variantes y 17 alusiones, todas ellas de periodistas.

El resumen de $\mathrm{R}$. Calvo Ortega es el siguiente: 18 variantes [3+0+11+4] y 134 alusiones $[80+0+37+17]$. Predomina el uso del nombre propio sobre todos los demás, pero sorprende no hallar ninguna mención puesta en boca de otros dirigentes. El reparto porcentual por bloques es éste en alusiones: a) $59^{\prime} 70 \%$, b) $0 \%$, c) $27^{\prime} 61 \%$ y d) $12^{\prime} 68 \%$. Y en variantes el siguiente: a) $16^{\prime} 66 \%$, b) $0 \%$, c) $61^{\prime} 11 \%$ y d) $22 ' 22 \%$.

\section{Conclusiones (provisionales)}

La división de la alusiones en cuatro grandes bloques, y sus correspondientes variantes, no agota el análisis de las denominaciones. En los estudios citados se alude a diferentes modos de designación. Éste es un capítulo muy polémico. ¿Qué quiere decir una forma "respetuosa", "reverencial" o "directa" según clasifican los estudiosos citados? ¿Cómo se puede encasillar, por ejemplo, un tuteo del tipo Felipe? ¿Es equiparable al de Julio? Bonnafous y Throsby discrepan en este apartado. Nosotros podríamos pensar en una división más simplificadora, más sencilla por lo tanto, pero más fiable a la vez, que estableciera por un lado a) formas neutras, y por otro b) todas las demás.

En el grupo neutro encajarían las formas correspondientes al español estándar: los usos del tipo nombre y apellido, don + nombre y apellido, señor + apellido, apellido solamente, los cargos, los enunciados como líder, secretario, presidente, coordinador + los grupos políticos de cada cual y los correspondientes a candidatos y variantes + presidente de Gobierno. Es decir, la inmensa mayoría de la alusiones.

En el grupo no neutro (metafórico, jocoso, peyorativo, familiar) estarían las demás, como sucede con Felipe, FG, don González, señor Felipe, tío Felipe, Felipe el cínico, González Líder, dios, dios González, primer espada, secretario general de Filesa; José María, pequeño Aznar, compañero Aznar; Julio, julius; candidato de la triste figura. 
La riqueza mayor está en el líder socialista lógicamente, pues es el que ocupa el puesto codiciado por todos, el de Presidente del Gobierno. Sin embargo no son hirientes en exceso las denominaciones no neutras. La campaña, en el medio estudiado aquí, carece de insultos y descalificaciones.

Mayor interés tiene el cotejo de las estadísticas. Según los cuadros anejos, todos los candidatos descansan en la apelación al nombre propio (ver cuadro I), es decir, el capital de un partido se apoya en el personalismo de su líder, entre el $80 \%$ y el $90 \%$ en González, Aznar y Anguita y próximo al 60\% en Calvo Ortega. Las variantes del apartado c) tienen una progresión creciente desde González hasta Calvo Ortega (22'12\%, 48'27\%, 50'00\% y $61^{\prime} 11 \%$ ) inversamente proporcional a su peso específico en la política española.

Pero lo más llamativo se da en el cotejo de los mismos datos entre unos y otros líderes, es decir, en lo que se refleja en el cuadro II. Si sumamos los porcentajes de los dos dirigentes de los partidos mayoritarios se obtiene en el grupo a) un $80^{\prime} 66 \%$ [ $\left.=43^{\prime} 41+37^{\prime} 25\right]$, en el b) el 100\%, en el c) un 62'68\% [=20'89+41'79] y en el d) un 71'16\% [=27'02+44'14]. Por lo que se refiere a las variantes, el predominio es también claro.

El cuadro III, con resultados globales, marca también las diferencias que socialistas y populares (más lo primeros que los segundos) tienen sobre los otros dos contendientes.

En el caso de F. González, la fuerza que supone el apartado b) incrementa el peso de su partido. Al líder y candidato de los socialistas, se vincula, por si alguien no lo supiera, que es el presidente del gobierno.

A falta del cotejo con otros medios de comunicación, en El Mundo es obvio el personalismo y el bipartidismo del que tanto se ha hablado en nuestra sociedad.

Al principio de este análisis he señalado que este estudio se puede insertar, en un sentido amplio, en la onomasiología. Lo que sorprende es la variedad que se recoge en las denominaciones sobre todo si no nos olvidamos de que todo esto ha salido de un único periódico y de apenas una quincena de días. 


\section{Cuadro I}

Felipe González

Alusiones
a)
$775=88^{\prime} 36 \%$
b) $\quad 30=342 \%$
a) $\quad 14=38.88 \%$
c) $\quad 42=4^{\prime} 78 \%$
b) $\quad 9=2500 \%$
d)
$30=3^{\prime} 42 \%$
c) $\quad 8=22 ' 22 \%$
d) $\quad 5=13 ' 88 \%$
Total...... $877=99.99 \%$
Total.. $36=99.98 \%$

José María Aznar

\section{Alusiones}

\section{Variantes}
a)
$655=82^{\prime} 91 \%$
b)
$2=0^{\prime} 25 \%$
c) $\quad 84=10^{\prime} 63 \%$
d)
$49=620 \%$
Total..... $790=9999 \%$

a)

$7=24^{\prime} 13 \%$

b)

$2=6.89 \%$

c)

$14=4827 \%$

d)

$6=20^{\prime} 68 \%$

Total.... $29=99.97 \%$

Julio Anguita

Alusiones

\section{Variantes}
a)
$65=83^{\prime} 33 \%$
a)
$4=28.57 \%$
b)
$0=0 \%$
b)
$0=0 \%$
c)
$38=11^{\prime} 94 \%$
c)
$7=50^{\prime} 00 \%$
d)
$15=4^{\prime} 71 \%$
d)
$3=21^{\prime} 42 \%$
Total...... $318=99^{\prime} 98 \%$
Total.....14 = $99.99 \%$

Rafael Calvo Ortega

Alusiones

\section{Variantes}

$\begin{array}{rrllrl}\text { a) } & 80 & =59^{\prime} 70 \% & \text { a) } & 3 & =16.66 \% \\ \text { b) } & 0 & =0 \% & \text { b) } & 0 & =0 \% \\ \text { c) } & 37 & =27^{\prime} 61 \% & \text { c) } & 11 & =61^{\prime} 11 \% \\ \text { d) } & 17 & =12^{\prime} 68 \% & \text { d) } & 4 & =22^{\prime} 22 \% \\ \text { Total....... } 134 & =99^{\prime} 99 \% & \text { Total... } & 18 & =99^{\prime} 99 \%\end{array}$




\section{Cuadro III}

\begin{tabular}{|c|c|c|c|c|}
\hline Alusiones: & a) & b) & c) & d) \\
\hline F. González: & $775=43^{\prime} 41 \%$ & 30 & $42=20^{\prime} 89 \%$ & $30=27^{\prime} 02 \%$ \\
\hline J. Ma Aznar: & $665=37^{\prime} 25 \%$ & 2 & $84=41^{\prime} 79 \%$ & $49=44^{\prime} 14 \%$ \\
\hline J. Anguita: & $265=14^{\prime} 84 \%$ & 0 & $38=18^{\prime} 90 \%$ & $15=1351 \%$ \\
\hline R. Calvo Ortega: & $80=4^{\prime} 48 \%$ & 0 & $37=1840 \%$ & $17=15^{\prime} 31 \%$ \\
\hline Totales.... & $1785=99^{\prime} 98 \%$ & 32 & $201=99.98 \%$ & $111=99^{\prime} 98$ \\
\hline
\end{tabular}

En el grupo b) no doy porcentajes porque no son necesarios ni en las alusiones ni tampoco en las variantes que ofrezco a continuación.

$\begin{array}{lllll}\text { Variantes: } & \text { a) } & \text { b) } & \text { c) } & \text { d) } \\ \text { F. González: } & 14=50^{\prime} 00 \% & 9 & 8=20^{\prime} 00 \% & 5=27^{\prime} 77 \% \\ \text { J.M A Aznar: } & 7=25^{\prime} 00 \% & 2 & 14=35^{\prime} 00 \% & 6=33^{\prime} 33 \% \\ \text { J. Anguita: } & 4=14^{\prime} 28 \% & 0 & 7=17^{\prime} 50 \% & 3=16^{\prime} 66 \% \\ \text { R. Calvo Ortega: } & 3=10^{\prime} 71 \% & 0 & 11=27^{\prime} 50 \% & 4=22^{\prime} 22 \% \\ \text { Totalles........... } & \mathbf{2 8}=\mathbf{9 9}^{\prime} \mathbf{9} 9 \% & \mathbf{1 1} & \mathbf{4 0}=\mathbf{1 0 0}^{\prime} \mathbf{0 0} \% & \mathbf{1 8}=\mathbf{9 9} \mathbf{9}^{\prime} \mathbf{9 8} \%\end{array}$

\section{Cuadro III}

Cifras totales

$\begin{array}{lll} & \text { Allusiones } & \text { Variantes } \\ \text { F. González: } & 877=41^{\prime} 38 \% & 36=37^{\prime} 11 \% \\ \text { J.M Aznar: } & 790=37^{\prime} 28 \% & 29=29{ }^{\prime} 89 \% \\ \text { J. Anguita: } & 318=15^{\prime} 00 \% & 14=14^{\prime} 43 \% \\ \text { R. Calvo Ortega: } & 134=66^{\prime} 32 \% & 18=18^{\prime} 55 \% \\ \text { Totalles............. } & 2119=99^{\prime} 98 \% & 97=99^{\prime} 98 \%\end{array}$

